\title{
Prevalence of Doping Use in Elite Sports: A Review of Numbers and Methods
}

\author{
Olivier de Hon · Harm Kuipers • \\ Maarten van Bottenburg
}

Published online: 29 August 2014

(c) Springer International Publishing Switzerland 2014

\begin{abstract}
The prevalence of doping in elite sports is relevant for all those involved in sports, particularly for evaluating anti-doping policy measures. Remarkably, few scientific articles have addressed this subject so far, and the last review dates back to 1997. As a consequence, the true prevalence of doping in elite sports is unknown. Even though it is virtually impossible to uncover the exact prevalence of a prohibited activity such as doping, various methods are available to uncover parts of this particular problem, which enables the circumvention (to a certain degree) of the issues of truthfulness, definition problems and the limits of pharmacological evidence. This review outlines the various methods that exist and presents the scarce data available in this area. It is concluded that a combination of questionnaires using the Randomised Response Technique and models of biological parameters is able to provide the statistical possibilities to reveal accurate estimates of this often undisclosed practice. Data gathered in this way yield an estimation of 14-39\% of current adult elite athletes who intentionally used doping.
\end{abstract}

O. de Hon $(\bowtie)$

Anti-Doping Authority The Netherlands, P.O. Box 5000, 2900 EA Capelle aan den IJssel, The Netherlands e-mail: o.dehon@dopingautoriteit.nl

\section{H. Kuipers}

Faculty of Health, Medicine, and Life Sciences, Maastricht University, Maastricht, The Netherlands

M. van Bottenburg

Utrecht University School of Governance, Utrecht,

The Netherlands
These period prevalences have been found in specific subgroups of elite athletes, and the available data suggest that the prevalence of doping is considerably different between sub-groups with varying types of sport, levels and nationalities. The above-mentioned figure of $14-39 \%$ is likely to be a more accurate reflection of the prevalence of intentional doping in elite sports than that provided by doping control test results (estimate of doping: 1-2\% annually) or questionnaire-based research (estimations between 1 and $70 \%$ depending on sport, level and exact definitions of intent and doping). In the future, analytical science may play a more important role in this topic if it may become feasible to detect very low concentrations of prohibited substances in sewage systems downstream of major sporting events. However, it is clear that current doping control test results show a distinct underestimation of true doping prevalence. It does not seem feasible to distil better estimates of the prevalence of doping based on performance indicators or ego documents because of the various existing effects that influence athletic performance. Such information can only be used as extra information to augment the accuracy of prevalence rates that have been found by using other techniques. True doping prevalence studies have been scarce in elite sports so far. With the correct application of the available scientific methods, preferably using harmonised definitions of the terms 'doping' and 'elite sports', more information on this topic may be gathered in a relatively short time. This would assist antidoping professionals in the future in order to evaluate the effects of possible anti-doping measures, and better antidoping policies would serve athletes who compete without doping. The existing anti-doping measures seriously impact the lives of elite athletes and their immediate entourage, which imposes a moral burden to evaluate these measures in the best possible way. 


\section{Key Points}

The prevalence of doping in elite sports is likely to be between 14 and $39 \%$, although this figure can differ widely in various sub-groups of athletes.

The prevalence of doping can be best measured using a combination of questionnaires using the Randomised Response Technique and available models of biological parameters.

Measuring the prevalence of doping in elite sports is important for both anti-doping policy discussions and for the athletes themselves. Trustworthy prevalence figures provide a tool for evaluating the effectiveness of anti-doping policies.

\section{Introduction}

The true prevalence of doping in elite sports is often discussed. Various methods exist to study doping prevalence, but recent revelations by various elite cyclists underlined a discrepancy between true prevalence figures and positive doping tests [1,2]. This discrepancy is probably not limited to cycling [3], and casts serious doubts on the effectiveness of current anti-doping policies.

The main aim of this article is to discuss the advantages and disadvantages of available methods to gather information on the prevalence of doping in elite sports: (1) laboratory-based chemical analyses; (2) questionnaires; (3) inferences from performances; and (4) inferences from ego documents. A secondary goal is to discuss the currently available scientific data on the prevalence of doping use in elite sports in order to estimate actual doping use. The last review on this subject was published in 1997 [4].

\subsection{Practical Limitations of Studying Doping}

Three inherent limitations are associated with trying to reveal prevalence figures for doping in elite sports. First, chemical analyses cannot detect all the doping substances or methods available to an athlete. The pharmacokinetics of doping substances are such that performance-enhancing effects often outlast the time window for detecting traces of a substance in an athlete's bodily specimen [5]. Over the last few years there has been an increasing number of antidoping rule violations (ADRVs) based on indirect (nonanalytical) evidence of the use of prohibited substances. Such efforts can be expected to narrow the gap between actual doping and analytical results. However, as yet, these cases are limited in number [3].
A second limitation is that of any study design that relies on personal input from athletes; they cannot be expected to be completely truthful, as doping is prohibited. Particularly when athletes are still active, there is an obvious barrier to discussing doping in detail. This limits the accuracy of data gathered using personal contacts.

Third, there is a definition issue. Some prohibited substances, such as cocaine, marihuana and alcohol, are also used in so-called 'social' settings without any intention to enhance athletic performance. Some athletes may not regard this as doping, while the anti-doping rules will flag this as an ADRV when traces of these substances are found in an athlete's urine during the competition, even when the actual use occurred several days before. When asked about their 'doping' such athletes may not provide full and correct information, even if they intend to cooperate truthfully with the researcher [6]. The opposite is also a confounder: an athlete may be convinced that he is breaking the rules even when the substance is in fact not prohibited. Such misunderstandings regarding the legal definition of 'doping' limit the interpretation of available data on this issue.

\subsection{The Need for Reliable Data}

Despite these inherent limitations, it is important to try and determine a reliable, clearly defined prevalence of doping in elite sports. For anti-doping professionals, such information allows for an evaluation of the effectiveness of their policies (preventive measures, education, tests, sanctioning regime, focus on drug trafficking, etc.). Such evaluations are currently essentially lacking in the field of anti-doping, which begs the question from some critics whether antidoping policies are legitimised at all [7-11]. The various efforts aimed at informing athletes of the existing antidoping rules (education, tests, sanctioning) require considerable resources. All these efforts are legitimised by the perception of as yet non-disclosed violations. But the true extent of the problem is seldom addressed, and so estimations on doping prevalence tend to vary to a large degree, starting from 'few' to 'all' athletes $[12,13]$. This also leads to popular but unfounded statements such as 'it is impossible to cycle a Tour de France without doping' or 'every finalist in an Olympic $100 \mathrm{~m}$ track final must have used doping'. Reliable scientific data would enable such general statements to be verified. In addition, factual information about doping prevalence would perhaps give more support to true clean champions.

\subsection{Definitions}

Definitions of the most essential terms in this review are outlined in Table 1. In this article, the term 'substances' should be read as 'substances and/or methods' so as to 
Table 1 Definition of terms

\begin{tabular}{|c|c|}
\hline Prevalence & $\begin{array}{l}\text { True point prevalence refers to a total number of identified cases in a specific population at a given point in time. When studying the } \\
\text { available data on doping, many data actually refer to period prevalences, signalling the occurrence of a condition within a } \\
\text { specified period of time (true incidences are absent altogether in this area). In this review, the word 'prevalence' will refer to al } \\
\text { cases identified within a specified population, in this case doping amongst elite athletes. The exact backgrounds of the available } \\
\text { data are mentioned where appropriate }\end{array}$ \\
\hline Doping & $\begin{array}{l}\text { The term 'doping' refers to the set of prohibited substances and/or methods as identified by the ruling body of the particular sport } \\
\text { Globally speaking, almost all sport federations follow the Prohibited List International Standard of the World Anti-Doping } \\
\text { Agency [14], which is reviewed and updated at least once a year. This means that the term 'doping' in this review does not reflect } \\
\text { other doping violations mentioned in the World Anti-Doping Code, such as whereabouts failures or trafficking }\end{array}$ \\
\hline Sports & $\begin{array}{l}\text { The term 'sports' is reserved for all activities that fit the broad definition as defined by SportAccord [110]. SportAccord currently } \\
\text { has } 91 \text { international sports federations as members, including both Olympic and non-Olympic sports. Generally speaking anti- } \\
\text { doping rules are only present in competitive sports, and non-competitive activities such as walking and fitness therefore receive } \\
\text { little interest in this review }\end{array}$ \\
\hline $\begin{array}{l}\text { Elite } \\
\text { sports }\end{array}$ & $\begin{array}{l}\text { Without defining a strict lower boundary for this term, we consider all athletes who compete at the level of international } \\
\text { championships and highest national championships as 'elite'. This includes juniors and adults in their respective age groups. So- } \\
\text { called 'masters athletes', being athletes who compete against similarly aged opponents once their athletic prime has passed, are } \\
\text { not considered 'elite' in the context of this review. The inclusion of the highest national championships makes this term broader } \\
\text { than solely those athletes who represent their countries at major sport events such as the Olympic Games, Commonwealth Games, } \\
\text { World Championships or continental championships but fits the current practice where Anti-Doping Organisations focus their } \\
\text { attention primarily on these levels }\end{array}$ \\
\hline
\end{tabular}

include all prohibited substances and methods that are mentioned on the official Prohibited List International Standard [14].

\subsection{Search Methods}

Data were extracted from personal files, as well as from a comprehensive literature search in the PubMed database without limits in search period. Key words were 'prevalence' or 'incidence', combined with 'doping' or 'performance', followed by individual inspection of titles and, if necessary, abstracts. Reviews and original articles focussing on elite athletes were always included; prevalence studies in other groups of athletes were only included if their content or methodology added something new to the previously collected studies.

\section{Laboratory-Based Chemical Analyses}

\subsection{Doping Control Test Results}

An obvious source of information for the prevalence of doping use is the result of doping tests, based on either urine or blood analyses. Since 2003, the World AntiDoping Agency (WADA) annually publishes an overview of Adverse Analytical Findings (AAFs) reported by official WADA-accredited laboratories [15]; the International Olympic Committee (IOC) did this in the years before (personal communications). These data encompass more than 50 different sports, including all Olympic and Paralympic sports. Table 2 lists these data, which are generally difficult to access publicly. WADA has improved the transparency of these data during the last few years, but detailed information on the exact substances found in which sports or laboratories is not provided. These are anonymous data by default, since a doping control laboratory does not know the identity of the athlete who produced the sample.

These data have various limitations. First, they only show what substances have been found at the time of sample collection. Detection windows of the various prohibited substances are highly variable, ranging from hours to months after last use [5, 16, 17]. Some effective doping substances have a very short detection window, especially when used in low doses, and thus cannot be traced days or even hours after administration. Intentional users of doping are known to employ such techniques, knowing that they will not be tested every day [1, 18, 19]. This means that doping tests, even when performed at irregular intervals at unexpected times, will never catch all athletes who dope.

A second limiting factor for detecting doping is the analytical capability of doping laboratories at the time of analysis. According to current anti-doping rules, re-analysis of older samples may be done up to 8 years after sample collection to benefit from improved analytical techniques. The cases where this was deployed, such as for methoxy polyethylene glycol-epoetin beta and methandienone, yielded some new doping cases, but these were only small in number, yet very high profile at times [20, 21]. In 2005, the French newspaper L'Equipe published the results of re-analysis for recombinant human erythropoietin (rhEPO) in samples from the 1999 Tour de France. These retrospective analyses, which at the time were judged to be legally inadmissible according to the anti-doping rules that were in place in 1999, but which later proved to be correct 
Table 2 Laboratory findings in doping tests 1987-2013 [15]

\begin{tabular}{|c|c|c|c|c|c|}
\hline Year & Doping tests $(n)$ & AAFs $(n)^{\mathrm{a}}$ & ATFs $(n)^{\mathrm{a}}$ & Total findings (AAFs + ATFs $)$ & Findings $(\%)^{\mathrm{b}}$ \\
\hline 1987 & 37,882 & & & 854 & 2.25 \\
\hline 1988 & 47,069 & & & 1,153 & 2.45 \\
\hline 1989 & 52,371 & & & 1,206 & 2.30 \\
\hline 1990 & 71,341 & & & 932 & 1.31 \\
\hline 1991 & 84,088 & & & 805 & 0.96 \\
\hline 1992 & 87,808 & & & 993 & 1.13 \\
\hline 1993 & 89,166 & & & 1,222 & 1.37 \\
\hline 1994 & 93,680 & & & 1,278 & 1.36 \\
\hline 1995 & 93,938 & & & 1,516 & 1.61 \\
\hline 1996 & 96,454 & & & 1,569 & 1.63 \\
\hline 1997 & 106,561 & & & 1,779 & 1.67 \\
\hline 1998 & 105,250 & & & 1,926 & 1.83 \\
\hline 1999 & 118,259 & & & 2,341 & 1.98 \\
\hline 2000 & 117,314 & & & 2,229 & 1.90 \\
\hline 2001 & 125,701 & & & 2,075 & 1.65 \\
\hline 2002 & 131,369 & & & 2,371 & 1.80 \\
\hline 2003 & 151,210 & & & 2,447 & 1.62 \\
\hline 2004 & 169,187 & & & 2,909 & 1.72 \\
\hline 2005 & 183,337 & & & 3,909 & 2.13 \\
\hline 2006 & 198,143 & & & 3,887 & 1.96 \\
\hline 2007 & 223,898 & & & 4,402 & 1.97 \\
\hline 2008 & 274,615 & 2,956 & 2,105 & 5,061 & 1.84 \\
\hline 2009 & 277,928 & 3,091 & 2,519 & 5,610 & 2.02 \\
\hline 2010 & 258,267 & 2,790 & 2,027 & 4,817 & 1.87 \\
\hline 2011 & 243,193 & 2,885 & 1,971 & 4,856 & 2.00 \\
\hline 2012 & 267,645 & 3,190 & 1,533 & 4,723 & 1.76 \\
\hline 2013 & 269,878 & 3,529 & 2,433 & 5,962 & 2.21 \\
\hline
\end{tabular}

$A A F s$ adverse analytical findings, ATFs atypical findings

a Available since 2008

b Percentage of findings (AAFs + ATFs) as a proportion of the total number of doping tests. Further explanations of the terms AAFs and ATFs can be found in WADA's Laboratory testing figures [15]

at least in the case of 1999 first-finisher Lance Armstrong, revealed that 20 samples showed signs of rhEPO out of a total of 67 extra analyses shown by the newspaper (point prevalence of $30 \%$ ) [22].

Third, the official laboratory data simply refer to the substances that have been found in an athlete's specimen, even when an athlete had a genuine therapeutic need for a particular substance. In such a case, the athlete may have a valid 'Therapeutic Use Exemption' (TUE) to use this substance. For example, an asthmatic using formoterol and budesonide will show up twice in the overview of AAFs, but this cannot be regarded as doping as long as therapeutic guidelines given by the doctor are followed. This means that the anonymous overviews of laboratory findings also possess an inherent overestimation, particularly of intentional doping.

An extra problem for assessing accurate prevalence data of doping is that most AAFs in the category 'anabolic steroids' refer to atypical steroid profiles, which do not constitute an ADRV. In such cases, additional testing is needed before such 'atypical' findings can be regarded as proof for doping. As shown in Table 2, WADA has reported the difference between AAFs and ATFs since 2008, but this distinction was not made in the years before. A large proportion of the reported AAFs are in fact not linked to ADRVs. This example also shows the difficulty in using these data in longitudinal analyses. The data that are published annually are based on the rules at that time [15, 23]. Since these rules may change, it is difficult, if not impossible, to compare these data over the years. The percentage of 'findings' in doping test results have fluctuated between 0.96 and $2.45 \%$ over the years. Analyses per country yield similar period prevalences, although the fluctuations may be somewhat larger [24-27]. 
A final major problem for obtaining accurate prevalence data is that it is impossible to derive the level of intentionality of doping use on the basis of AAFs or ADRVs alone. Preliminary analyses in the sport of tennis showed that a majority of ADRVs are most likely to be unintentional [28, 29]. The legal description of ADRVs in WADA's World Anti-Doping Code does not address the issue of whether the rules have been broken knowingly or inadvertently, although this can play a role in the determination of the exact sanction once a violation has been established. This strict focus on violations per se has led some individuals to conclude that there is no such thing as 'unintentional doping'. Yet, fundamentally speaking, there is a big difference between intentional and unintentional violations. Also, when evaluating the effectiveness of the existing policies, it is important to make a distinction between deliberately violating the existing rules and socalled 'accidents'. The backgrounds of ADRVs may require completely different educational efforts.

\subsection{Population Estimates Based on Biological Parameters}

An indirect way of estimating the prevalence of doping in a group of athletes is to look at the distribution of certain biological parameters. Some work has been performed in this area regarding blood parameters, which gives information on the prevalence of blood-related doping methods, such as erythropoietin-use and other haematological manipulations. In elite cycling, the percentage of 'extreme' (and therefore suspect) haematological values has dropped between 2001 and 2009 from 11 to $2 \%$ [30], which can be regarded as an indication that haematological doping (or at least 'extreme' doping methods) has decreased during these years. In other sports, similar attempts have been made to link possible doping use to individual blood parameters [31, 32]. A more sophisticated method has been introduced into the area of anti-doping by Sottas et al. [33]. It is based on a Bayesian model that includes relevant parameters and empirically validated data analysis of both users and non-users of doping. Given a certain populationwide dataset, the model identifies what percentage of the data can be expected to be 'unnatural'. The final result is an estimate of blood manipulation [34, 35].

A disadvantage of thus obtained prevalences is that the model uses certain assumptions, especially regarding as to what constitutes 'normal' and 'supra-physiological' values. Subsequently, it is able to produce different outcomes based on the same input. As an example, Sottas et al. [36] present two columns of possible prevalences of blood manipulations in track and field, dependent on the possible use of 'microdosing' doping. This difference in pre-calculation hypotheses leads to sometimes considerable differences in prevalences (up to $30 \%$ in \% points) but, generally speaking, this method provides good insight into doping practices in certain (sub)populations. The most likely estimate is that, in the period between 2000 and 2010, $14 \%$ of all elite athletes in track and field have engaged in some sort of illegal blood manipulation [36]. WADA's AAF reporting has shown much lower period percentages in this sport: $1.0 \%$ in 2011 and $0.8 \%$ in 2010 [15]. Weighing all circumstances, the estimate of $14 \%$ seems far more accurate, noting that this estimate only relates to blood-related doping practices. It is also interesting to note that this study showed a large variation in likely doping between countries, even in the same events, suggesting that doping is not per se a sports-wide problem, but has selective origins and is limited by socioeconomical structures.

Other sports, such as cycling, football, cross-country skiing, speed skating, and biathlon, possess similar data [30, 32, 37-39] and it would be relevant to see similar analyses in these sports, including distributions per country, per team or per performance level. This is interesting since in cross-country skiing it has been shown previously that those athletes with the highest haemoglobin values are more likely to finish in the top places in elite competitions [38], whereas such a relationship is absent in speed skating $[39,40]$. Such differences may occur as a result of differences in physiological and biomechanical determinants of performance in the specific sport and/or sociological differences in doping/permissiveness, but such discussions should be based on clear and unambiguous data on the prevalence of doping.

The same principle can also be applied to testosteronerelated analyses [41], but this method has not yet been fully implemented. This means that the Sottas et al. models of doping prevalence currently reveal only part of the picture: they only describe 'haematological doping'. However, they do, in all likelihood, refer solely to intentional doping practices. Although haematological values are known to vary because of various permitted behaviours (such as altitude training) or clinical factors (such as dehydration, sickness), the strength of analysing blood distributions is that the models account for all such factors. The main setbacks of this source of information are the inability to link the available data to individual doping, and the currently very limited availability of actual data from the world of elite sports [42].

A different approach to looking at doping at a population level could be the chemical analysis of waste water downstream of the sewage system of a selected population. An example of this approach has been published by Schroder et al. [43] near fitness centres. It is an atypical approach that is able to yield general information on the quantities of doping. Unfortunately, current analytical capabilities make it impossible to deploy this for all doping 
substances, and obviously it will never be possible to link these results to individual doping use. However, it is an interesting option to test the water downstream of athlete villages at major events, such as the Olympic Games, as it is a relatively easy and cheap way of gathering information on a large group of people and to see whether these results reflect similar levels of prohibited substances as found in official doping tests. This principle has been used in prevalence studies on social drugs before, but, as yet, has still to prove its practical usefulness [44].

\subsection{Conclusion from Laboratory-Based Chemical Analyses}

Doping control test results yield reproducible data and an anonymous, yet individual, account of the presence of doping substances in an athlete's body. However, in practice, these data have limited statistical value, since they include an unreported percentage of legitimate therapeutic use of medications and an unknown percentage of unintentional doping infractions. These data are also much dependent on changes in the regulations of reporting AAFs at the moment of sample collection. However, the most important drawback, is the dependence on underlying testing procedures and on the availability of approved analytical methods, which sometimes lag behind doping. In conclusion, the annual percentage of AAFs cannot be expected to reflect the actual prevalence of doping.

Population-based models based on physiological parameters can be expected to yield a far better estimate of actual doping period prevalences. The major drawback of this approach is not the inherent uncertainty of modelling, but that this approach has only been reported in a subset of athletes in track and field, and only in relation to haematological doping. That particular prevalence figure (14\%) is an extra indication that the percentage of AAFs in many sports modalities is an underestimate of true doping prevalence. More information is available to various anti-doping organisations, but so far these have not been made public.

\section{Questionnaires}

\subsection{Standard Questionnaires}

Straightforward questioning about possible doping is very rarely used in scientific studies involving elite athletes. Many studies have been conducted with North-American high school athletes or European students, yielding percentages of 1-12\% [45-59]. These studies have focused primarily on anabolic androgenic steroids. Whenever subgroups of non-competitive athletes who train in fitness centres are included, period prevalences rise up to $70 \%$
[60-69]. But these are not the target groups for this review. Petroczi et al. [70] claim a self-reported doping prevalence in Olympic sports of between 1 and $30 \%$, but fail to back up this statement with references.

Elite athletes' doping habits were reviewed in 1997 by Laure [4], who estimated self-reported doping amongst adult athletes at 5-15\% (presumably period prevalence). This sort of research has received little attention since. This is likely because self-response questionnaires have limited value, especially on controversial issues such as doping, since they have the inherent risk of drawing socially accepted answers in a possibly biased response group [71, 72]. Thevis et al. [59] effectively showed, by means of chemical analyses, that elite sport students do not report all use of prohibited substances in questionnaires. However, self-assessment questionnaires have been shown to have some validity in studies focusing on non-athletic drug abuse [73, 74].

A strategy to navigate around these pitfalls is to present the issue as a hypothetical question. The standard example that is often (mis)used in discussions about doping in elite sports is the infamous question 'if you would be offered a magic drug that would guarantee that you would win all important competitions in the next 5 years, but you will die from it shortly afterwards-would you take it?' This question was first asked by author Bob Goldman to 198 of his acquaintances, who all participated in strength sports [75]. The results of this 'study' (a staggering $52 \%$ said 'yes') are very often extrapolated to all sorts of populations of elite athletes, whereas an attempt to interpret these data as being applicable to all strength athletes seems already too much extrapolation. This quintessential urban legend obviously lacks any scientific merit. Recent research has shown that, in a more representative field of elite athletes in the sport of athletics, this percentage does not reach $2 \%$ [76].

\subsection{Randomised Response Technique}

The two biggest confounders in regular questionnairebased research, a biased response group and amongst responders the tendency to give socially desirable answers, can be effectively tackled by an alternative questionnaire approach: the 'randomised response technique' (RRT) [77]. This is a technique where the anonymity of the answers is increased by a deliberate mathematical confounder. Respondents first engage in an activity with a known stochastic distribution (e.g. rolling a dice) and depending on this outcome, they either are obliged to answer 'yes', 'no', or the truth. The researcher does not know the outcome of the first activity, and thus does not know whether the given answer is based on the forcedresponse or the truth. After the dataset has been collected, it 
can be mathematically calculated how many of the answered 'yes' and 'no' must originate from the introduced element of chance, and (thus) how much of 'yes' and 'no' answers must have been truthful. The idea is to enlarge the confidence of the subjects because of the introduced anonymity. The element of play may also play a role in the respondents' willingness to cooperate. The downside is that a certain level of uncertainty must be accepted, as the outcome will not be a single percentage, but a confidence interval. It also means that there are no individual data points; this method will only yield population averages.

The RRT has been used and tested in a variety of socially 'undesirable' behaviour situations since the 1960s, such as social welfare fraud, law-abiding behaviour and sexual habits. Each and every time, the prevalences arising from this study design are higher than those that result from traditional questionnaires, and research has shown that these higher prevalences are closer to the truth [77-79].

In doping-related research, only one study has been published that used RRT to investigate intentional doping amongst elite adult athletes [79]. They found that between 26 and $48 \%$ of a group of 448 German Olympic-level athletes admitted to having used doping at some point in their career. The last-year period prevalence was estimated at 20-39\%. The exact reliability of the statistical calculations is not reported. In Germany, RRT has also been applied for doping-related research in two other groups of athletes and in the Netherlands it has been applied once (Table 3) [72, 80, 81]. All these studies have yielded higher prevalences than previously found in regular questionnaire research. For the purpose of doping research, one anticipated aspect cannot be tackled by RRT: a respondent might still be inclined to lie because of the possible consequences on the image of his or her sport, since the athlete is informed that the outcomes will be used for that purpose. Current methods are unable to take this aspect into account.

\subsection{Conclusions from Questionnaires}

Questionnaire-based research indicates that somewhere between 1 and $70 \%$ of all athletes have used doping at some point in their career, depending on their sport and level [45-69]. It is difficult to compare the studies that have been performed because of varying definitions of 'sport', 'elite level' and 'use of doping'. Traditional questionnaires have a large caveat because their outcomes are prone to socially desirable answers, and as such are likely to underestimate true doping prevalence. The sole study involving adult elite athletes that tried to control for this confounder found a lifetime prevalence of $26-48 \%$ and a last-year prevalence of 20-39\% [79]. This figure needs to be confirmed in different groups of athletes from different nationalities. These sorts of studies currently give the most accurate estimations of doping use in sports. An extra benefit of using RRT questionnaires is that the level of intentionality can be added into the study design.

\section{Inferences from Performances}

\subsection{Athletic Performance and Non-Peer-Reviewed Literature}

It is tempting to attribute outstanding performances to the alleged use of doping [82, 83]. The main problem with such a line of thinking is that the athlete will always lose in any such discussion: no matter how much he trains without the use of any prohibited substance, as soon as he excels he is, by default, a doping suspect. The essence of sport is to excel, and if excelling becomes synonymous with suspicions of cheating, each and every sport performance turns into an attack on the essence of sport itself. If such reasoning persists, this will seriously jeopardise the credibility of sport.

Especially in cycling, there are a number of (semi)scientific websites that try to link performances in time trials or standardised circuits or climbs (expressed in time or in power outputs) to doping confessions or allegations [8486]. These efforts have not yet reached the scientific, peerreviewed literature. They conclude unequivocally that current champions do not reach the performance levels of the best riders of the 1990s or early 2000s. However, it is difficult to make a direct link to doping. In addition, it is possible that performances drop because the amount of doping has decreased, even though the number of individuals who dope may not have decreased.

Table 3 Period prevalence of doping in various target groups using randomised response technique questionnaires

\begin{tabular}{llll}
\hline Publication & Target group & $n$ & Prevalence of doping (\%) \\
\hline Pitsch et al. [79] & Adult elite & 448 & 26-48 Ever; \\
& & & $20-39$ Last year \\
Striegel et al. [72] & Junior elite & 480 & $3-11$ Ever \\
Simon et al. [81] & Fitness centre visitors & 500 & $8-17$ Ever \\
Stubbe et al. [80] & Fitness centre visitors & 447 & 5-23 Last year \\
\hline
\end{tabular}




\subsection{Athletic Performance and Peer-Reviewed} Literature

For the purposes of this review, the more scientific explorations of the relationship between athletic performances and doping-related issues bear some significance. The previously mentioned finding that, in the 1990s, most top finishers in cross-country skiing have the highest haematological values suggests that haematological doping in that specific culture was performance determining [38]. In such a homogenous group of elite athletes, one would not expect a linear relationship between oxygen transport capability and performance as, in elite sports, it is often not as much the physiological training status but small details such as 'form on the day' or psychological focus that determine who wins and who fails to make the podium. Athletic capabilities are a prerequisite to reach the top, but not necessarily a ticket to win [87]. Unfortunately, this approach does not enable the calculation of a prevalence of doping and may serve only as a hint.

Another aspect of performances and doping use was studied by Seiler et al. [88]. They looked at the relative performances between men and women in various power events (running, swimming, speed skating) and noticed that these two groups grew closer to each other up until approximately 1990, after which the gender gap increased again. Discussing various possible reasons for this trend, they conclude that the most likely reason is the advent of out-of-competition testing in the late 1980s, making it more difficult for athletes to use anabolic steroids during training periods. Anabolic steroids, all derived from testosterone, can be expected to have more performanceenhancing properties in females than in males [89]. These findings have been confirmed in later, more extensive, statistical calculations [90-92].

An innate problem with trying to link performances to possible doping infractions is that athletic performances are influenced by many factors, such as talent, improvements in training techniques, nutrition, psychological support, and changes in equipment and environment. Over time, athletic achievements tend to improve in every sport, but this does not mean that a failure to progress or even a slight drop in top performances mean that these can be related to doping patterns; they may just as well relate to one or more of the other factors that influence performance. Pure statistical studies into the times of elite cyclists in various races failed to reach a clear conclusion [93, 94], and this variability in factors that influence the final outcome of a race are most probably the reason to explain this ambiguity. Ernst and Simon speculated that recent improvements in sprinting performance in athletics could be indicative of a novel, very effective doping procedure (with insulin-like growth factor-1 being the primary candidate), but they also could not prove such assumptions [95].
The most basic disadvantage of inferences from performances is that even though these examples (haematogical values, gender gap, or other) yield information on the trends of suspected doping, they will never give detailed information on a true doping prevalence percentage, let alone in individual cases. In theory, one could do a similar exercise with performances as for the haematological values as discussed in Sect. 2.2: modelling what is 'normal' and estimating what is not. This has not yet been performed in practice. A serious limitation to this approach is that one would need to choose a standardised performance measurement and study this extensively. It is not likely that such data will be available.

\subsection{Conclusions from Performance Inferences}

Analyses of performance data may suggest general trends in doping patterns, but such information can only be used to confirm findings that are collected by other methods. For example, the relative performance gap between male and female athletes has given some information in sport events that are highly dependent on muscular strength and power. These data give an indication that anti-doping efforts influence performances, and that, on a group level, doping patterns have changed in the last 30 years in various sports. However, such data cannot be linked to the prevalence of doping. It can be concluded that, on the basis of performances alone, an individual assessment on possible doping is simply not possible, and, in addition, any attempt to try to do this will violate the essence of sport. Linking extraordinary athletic performances to doping use is highly insulting to clean champions. Both scientifically and morally it is not recommended to try and link performance levels to doping use; at best performances can be used to identify general influences of anti-doping measures on the entire population of elite athletes.

\section{Inferences from Ego Documents}

Published accounts of personal experiences, either in autobiographical books or press interviews, give insight into the environment in which an athlete performs or performed. Especially in cycling, various autobiographies have been published that included self-admitted doping [19, 87, 96-99]. Other sports have also been put under the spotlight [12, 100, 101]. Such information is never neutral, but a collection of individual accounts may serve as a socio-cultural description of perceived doping use amongst fellow competitors. These ego documents are the practical equivalents of case reports in the medical scientific literature. As such, they may serve as a particular data source for the subject of doping use in elite sports, but they will never 
produce reliable prevalences. As they are also partly commercially induced, the information on the individual level is doubtful. Their value is in pinpointing certain sociological constructs, and the perceptions of doping use by other competitors. These can also be studied by more scientific methodologies such as face-to-face interviews or participant observations, which have already been used in doping studies although not very often [18, 102, 103]. It should be taken into account that humans have a tendency to legitimise their own behaviours by their perception that many others do the same, even if this perception may be inaccurate [104].

\subsection{Conclusions from Ego Documents}

In theory, a study could be conducted to make an inventory of perceived doping use by elite athletes amongst their direct competition and possibly in other sports. Social networking studies or other sociological approaches may yield interesting qualitative results on the expected degree of doping use. In the end, such figures will mainly reflect the aura of doping, not doping itself. Ego documents from elite athletes will be able to give a hint of doping prevalence in the past, and may confirm data that have been collected by other methods. However, they are not likely to give credible factual information.

\section{Discussion}

WADA's Director General, David Howman, has stated that he expects that true doping amongst elite athletes is likely to be 'a double-digit figure' [105]. It is striking that the person who may be the best informed person in the world on this subject can do no better than an educated guess when asked about the prevalence of doping use. It is an area in which scientists may be of help to diminish the level of uncertainty.

\subsection{Methodological Aspects of Studying the Prevalence of Doping}

A combination of questionnaires using the RRT and models of biological parameters provide statistical possibilities to reveal accurate estimates of this often undisclosed practice. Unfortunately, these techniques have rarely been applied in elite sports.

It should be kept in mind that these methodologies will only be able to provide an estimate, with confidence intervals on either side of the point estimation; they yield population-based averages without the possibility to draw conclusions on the individual level. However, this uncertainty is much more preferable than the flawed exact numbers that chemical-based analyses show. This does not mean that doping tests have no value for anti-doping purposes; it merely shows that these data should not be used to claim knowledge on the accurate prevalence of doping use, especially in the format in which WADA is currently publishing these figures. The value of doing tests is in providing the strongest possible juridical proof that someone used doping. However, the robustness on the individual level cannot be extrapolated to the group level.

Based on the available evidence, it can be concluded that the prevalence of doping can be very different between sports, countries, and training groups. This has been shown extensively in gyms, and the limited data available in elite sports show a similar picture. Doping tends to concentrate in particular athletic groups who share a coach, trainer, doctor, manager, or other person with a permissive attitude towards doping. The International Association of Athletics Federations (IAAF) study, being the single available scientific description of doping in world-class sports, shows that, at least in athletics, this number is largely dependent on the country for which one is competing, presumably because doping is not so much an individual decision, but rather a final outcome of a social environment that is rather permissive towards doping [18, 106, 107].

Doping prevalence is also likely to vary between levels of play. The analysis by Maquirriain [28] of tennis-related ADRVs indicated that the prevalence of doping in this sport was in fact lower at the highest levels of the sport. It can be imagined that, at lower levels, the occurrence of 'accidents' (i.e. non-intentional ADRVs) is higher because of less than optimal doping education, although this assumption cannot yet be substantiated by any available data.

\subsection{Estimating the Prevalence of Doping in Elite Sports}

With so much attention given to doping in elite sports, and after almost a decade of intensified anti-doping research since the involvement of WADA in global anti-doping efforts, it is disappointing to see that only two studies have given a good insight into the prevalence of doping in a certain subpopulation of elite athletes: Pitsch et al. [79] in Germany and Sottas et al. [36] in athletics. These approaches should be used more extensively in many more subpopulations in order to reveal the effects of anti-doping measures and to gain as much insight as possible into the central question of anti-doping initiatives: how many athletes are resorting to doping substances or methods? Based on the currently available data, the most likely general period prevalence amongst adult elite athletes is the estimate originating from Germany based on RRT questionnaires: $20-39 \%$ in the last year [79]. This estimate can be 
supplemented with the population estimates based on biological value parameters in track and field: $14 \%$ of 'haematological' doping between 2000 and 2010 (Table 4) [36]. This fits rather well with the scarcely available results of re-analysis of older samples when new analytical techniques have been developed, as discussed in Sect. 2.1. These figures obviously need further substantiation in different groups before we can use doping prevalence estimates in policy evaluations.

In the annual reports of doping tests results, WADA limits itself to the publication of all AAFs and has not yet established an overview of ADRVs. Without such information, it is extremely difficult to evaluate the effectiveness of doping tests. Even without this essential information, it can be concluded that doping tests in their current form will show only a small percentage of intentional doping users. One might argue that, if the average length of a career in elite sports is 10 years, an approximate $1 \%$ of AAFs each year will result in 'catching' $10 \%$ of the entire elite athlete population. But this figure is still lower than the currently available best estimate of the prevalence of doping.

It is striking to see that a study into the use of a permitted substance that might be performance enhancing (nicotine) showed a prevalence of use of $19-56 \%$, dependent on the sports modality [108]. If the entire doping test system is indeed unable to keep the use of prohibited substances at a lower level than a permitted substance, it adds to the idea that current anti-doping testing is far from effective in curbing doping. It is also disconcerting that calls for more clarity in this area that were made more than 25 years ago have not yet yielded much progress [109]. There has been very little progress since the review by Laure [4] in 1997.

\subsection{Future Guidelines and Research Agenda}

Ideally, the prevalence of doping in all sports and at different levels should be monitored regularly. The most promising tools are questionnaire-like studies using the RRT and population estimates based on physiological variables. These two approaches offer the most accurate objective data on the prevalence of doping and can thus be expected to approximate the truth as closely as possible. One should accept that it is impossible to generate true prevalence figures of any prohibited activity, but modern science provides several possibilities to come close to reality. Anti-doping professionals have not yet taken full advantage of these techniques - or if they have, they have not published them in order to be scrutinised by peer scientists. When analytical science continues to progress, it may become possible in the future to collect data from sewage systems downstream of major sport events.

Reliable information on the prevalence of doping is necessary to perform policy evaluations. However, this is a far cry from current practice. We propose that, first, a harmonised approach to collecting data on prevalence of doping is agreed upon. WADA could be a leading organisation to draft guidelines on how to perform such actions. We propose that the definitions of 'doping' and 'elite sports' are used as they are in this article, and that 'prevalence of doping' will be operationalised as both the lastyear and lifetime incidence of intentional use of one or more prohibited substances with the intention to enhance performance in the sport of the athlete involved. Point prevalences or incidence figures may have additional value, but, given the current state of affairs in this field, it is proposed to focus predominantly on period prevalences in order to optimise comparability.

Table 4 Overview of estimates of the period prevalence of doping amongst elite athletes based on different analysis techniques

\begin{tabular}{llc}
\hline Analysis techniques & Estimated prevalence & Remarks \\
\hline $\begin{array}{l}\text { Doping control test results } \\
\begin{array}{l}\text { Population estimates based } \\
\text { on biological value } \\
\text { parameters }\end{array}\end{array}$ & $1-2 \%$ Last year [15] & $\begin{array}{c}\text { Stable figure for the last 25 years. Not likely to reflect true } \\
\text { intentional doping (see Sect. 2.1) } \\
\text { Blood manipulations in elite athletes in athletics; data on other } \\
\text { sorts of doping or sports modalities as yet unavailable } \\
\text { (see Sect. 2.2) }\end{array}$ \\
$\begin{array}{l}\text { Standard questionnaires } \\
\text { Mostly performed on adolescents and/or students; little research in } \\
\text { elite sports (see Sect. 3.1) }\end{array}$ \\
$\begin{array}{l}\text { Randomised response } \\
\text { questionnaires }\end{array}$ & $1-15 \%$ [4, 45-59] & $\begin{array}{c}\text { German athletes; data on other nationalities or sports modalities as } \\
\text { yet unavailable (see Sect. 3.2) }\end{array}$ \\
$\begin{array}{l}\text { Inferences from athletic } \\
\text { performances }\end{array}$ & $-11 \%$ Lifetime (junior) [72] & $\begin{array}{c}\text { Popular input for doping-related discussions but impossible to } \\
\text { reflect prevalence of doping (see Sects. 4.1, 4.2) }\end{array}$ \\
$\begin{array}{l}\text { Inferences from ego } \\
\text { documents }\end{array}$ & - & $\begin{array}{c}\text { Give some insight into the sociological background of doping and } \\
\text { perceived prevalence, but not true prevalence (see Sect. 5) }\end{array}$ \\
\hline
\end{tabular}




\section{Conclusion}

The most accurate way of estimating the prevalence of doping in elite sports is by using a combination of questionnaires using the RRT and models of biological parameters. So far, these evaluations have not been performed very often, or at least they have not been published. All doping-related discussions and decisions would be strengthened if this vital piece of information, i.e. scientifically reliable information on the prevalence of doping, becomes more readily available.

Current data suggest that 14-39\% of elite athletes are doping, but this figure needs further confirmation in different groups of athletes with varying levels and backgrounds. Doping prevalence can be expected to fluctuate substantially between different groups. However, the prevalence figure can be expected to be far higher than the average of 1-2\% of athletes who are caught with doping substances, or their metabolites, in their system. There are many efforts underway to close this gap, but this process is by no means complete.

Evaluations of the prevalence of doping use are not only interesting for sports fans and journalists. They are necessary for anti-doping professionals to enable true evaluation of the effectiveness of their policies. If the non-dopers are cheated by the dopers too often, and when doping tests are insufficient to control doping use in a meaningful manner, anti-doping efforts are doomed to fail. This is not a problem for the anti-doping professionals, but first and foremost for the athletes they have vowed to protect. Tools to evaluate the prevalence of doping use in sports are readily available; they only need to be used more often.

Acknowledgments OdH started the initiative to write this review, collected all literature and wrote most of the text. Both MvB and HK contributed to the set-up, structure and content. OdH holds the position of Manager Scientific Affairs for the national anti-doping organisation of the Netherlands. None of the authors have any other potential conflicts of interest that are directly relevant to the content of this review.

The issue of prevalence of doping in elite sports has been thoroughly discussed with many anti-doping professionals and athletes over the past few years, and all these colleagues and athletes are gratefully acknowledged for their enthusiasm and critical questions. The time to write this review was made available by means of a grant from the Dutch Ministry of Health, Welfare, and Sports.

\section{References}

1. USADA. U.S. postal service pro cycling team investigation. Colorado Springs, United States of America: United States AntiDoping Agency; 2012.

2. Sorgdrager W, van Bottenburg M, Goedhart E. Joining or Quitting [Original Title: 'Meedoen of Stoppen']. Arnhem, The Netherlands; 2013.
3. WADA. WADA seeks stakeholder feedback on Working Group Report: lack of effectiveness of testing programs. Montreal, Canada 2013 [30 May 2013]; Available from: http://playtrue. wada-ama.org/news/wada-seeks-stakeholder-feedback-on-workinggroup-report-lack-of-effectiveness-of-testing-programs/?utm_ source $=$ rss\&utm_medium $=$ rss\&utm_campaign $=$ wada-seeksstakeholder-feedback-on-working-group-report-lack-of-effecti veness-of-testing-programs.

4. Laure P. Epidemiologic approach of doping in sport. A review. J Sports Med Phys Fitness. 1997;37(3):218-24.

5. Hatton CK. Beyond sports-doping headlines: the science of laboratory tests for performance-enhancing drugs. Pediatr Clin North Am. 2007;54(4):713-33 (xi).

6. Lentillon-Kaestner V, Ohl F. Can we measure accurately the prevalence of doping? Scand J Med Sci Sports. 2011;21(6): e132-42.

7. D'Angelo C, Tamburrini C. Addict to win? A different approach to doping. J Med Ethics. 2010;36(11):700-7.

8. Kayser B, Mauron A, Miah A. Viewpoint: legalisation of performance-enhancing drugs. Lancet. 2005;366(Suppl 1):S21.

9. Kayser B, Mauron A, Miah A. Current anti-doping policy: a critical appraisal. BMC Med Ethics. 2007;8:2.

10. McNamee MJ, Tarasti L. Juridical and ethical peculiarities in doping policy. J Med Ethics. 2010;36(3):165-9.

11. Savulescu J, Foddy B, Clayton M. Why we should allow performance enhancing drugs in sport. Br J Sports Med. 2004;38(6): 666-70.

12. Berning JM, Adams KJ, Stamford BA. Anabolic steroid usage in athletics: facts, fiction, and public relations. J Strength Cond Res. 2004;18(4):908-17.

13. Jenkins PJ. Growth hormone and exercise: physiology, use and abuse. Growth Horm IGF Res. 2001;11(Suppl A):S71-7.

14. WADA. The 2013 Prohibited List International Standard. Montreal, Canada: World Anti-Doping Agency; 2012.

15. WADA. Laboratory testing figures. Montreal, Canada 2012 [30 May 2013]; Available from: http://www.wada-ama.org/en/ Science-Medicine/Anti-Doping-Laboratories/Laboratory-TestingFigures/. Accessed 11 July 2014.

16. Bowers LD. The analytical chemistry of drug monitoring in athletes. Annu Rev Anal Chem (Palo Alto Calif). 2009;2: 485-507.

17. Catlin DH, Fitch KD, Ljungqvist A. Medicine and science in the fight against doping in sport. J Intern Med. 2008;264(2):99-114.

18. Lentillon-Kaestner V. The development of doping use in highlevel cycling: from team-organized doping to advances in the fight against doping. Scand J Med Sci Sports. 2013;23(2): 189-97.

19. Voet W. Prikken en slikken [original title: Massacre a la chaine]. Roeselare: Roularta Books NV; 1999.

20. IOC. IOC disqualifies four medallists from Athens 2004 following further analysis of stored samples. Lausanne, Switzerland 2012 [30 May 2013]; Available from: http://www.olympic. org/news/ioc-disqualifies-four-medallists-from-athens-2004following-further-analysis-of-stored-samples/184931.

21. CNN. Ramzi stripped of Olympic $1500 \mathrm{~m}$ gold. Atlanta, USA 2009 [30 May 2013]; Available from: http://www.cnn.org/2009/ SPORT/11/18/athletics.olympics.ramzi.doping/index.html.

22. Le Ressiot D. Mensonge Armstrong [The Armstrong Lie]. L'Equipe. 2005;2005:23.

23. Verroken M. Ethical aspects and the prevalence of hormone abuse in sport. J Endocrinol. 2001;170(1):49-54.

24. Bahr R, Tjornhom M. Prevalence of doping in sports: doping control in Norway, 1977-1995. Clin J Sport Med. 1998;8(1): $32-7$.

25. Palmer W, Taylor S, Wingate A. Adverse analyzing-a European study of anti doping organization reporting practices and 
the efficacy of drug testing athletes. Switzerland: UNI Global Union; 2011.

26. Strano Rossi S, Botre F. Prevalence of illicit drug use among the Italian athlete population with special attention on drugs of abuse: a 10-year review. J Sports Sci. 2011;29(5):471-6.

27. van der Merwe PJ, Kruger HS. Drugs in sport-results of the past 6 years of dope testing in South Africa. S Afr Med J. 1992;82(3):151-3.

28. Maquirriain J. Epidemiological analysis of doping offences in the professional tennis circuit. J Occup Med Toxicol. 2010;5:30.

29. Pluim B. A doping sinner is not always a cheat. Br J Sports Med. 2008;42(7):549-50.

30. Zorzoli M, Rossi F. Implementation of the biological passport: the experience of the International Cycling Union. Drug Test Anal. 2010;2(11-12):542-7.

31. Videman T, Lereim I, Hemmingsson $P$, et al. Changes in hemoglobin values in elite cross-country skiers from 1987-1999. Scand J Med Sci Sports. 2000;10(2):98-102.

32. Manfredini F, Carrabre JE, Litmanen H, et al. Blood tests and fair competition: the biathlon experience. Int J Sports Med. 2003;24(5):352-8.

33. Sottas PE, Robinson N, Saugy M, et al. A forensic approach to the interpretation of blood doping markers. Law Probab Risk. 2008;7(3):191-210.

34. Sottas PE, Robinson N, Saugy M. The athlete's biological passport and indirect markers of blood doping. Handb Exp Pharmacol. 2010;195:305-26.

35. Sottas PE, Saudan C, Saugy M. Doping: a paradigm shift has taken place in testing. Nature. 2008;455(7210):166.

36. Sottas PE, Robinson N, Fischetto G, et al. Prevalence of blood doping in samples collected from elite track and field athletes. Clin Chem. 2011;57(5):762-9.

37. Vouillamoz M, Thom C, Grisdale R, et al. Anti-doping testing at the 2008 European football championship. Drug Test Anal. 2009;1(11-12):485-93.

38. Stray-Gundersen J, Videman T, Penttila I, et al. Abnormal hematologic profiles in elite cross-country skiers: blood doping or? Clin J Sport Med. 2003;13(3):132-7.

39. Kuipers H, Moran J, Dubravcic-Simunjak S, et al. Hemoglobin level in elite speed skaters from 2000 up to 2005, and its relationship with competitive results. Int $\mathrm{J}$ Sports Med. 2007;28(1):16-20.

40. Kuipers H, Moran J, Mitchell DW, et al. Hemoglobin levels and athletic performance in elite speed skaters during the Olympic season 2006. Clin J Sport Med. 2007;17(2):135-9.

41. Sottas PE, Saudan C, Schweizer C, et al. From population- to subject-based limits of T/E ratio to detect testosterone abuse in elite sports. Forensic Sci Int. 2008;174(2-3):166-72.

42. Schumacher YO, Saugy M, Pottgiesser T, et al. Detection of EPO doping and blood doping: the haematological module of the Athlete Biological Passport. Drug Test Anal. 2012;4:846-53.

43. Schroder HF, Gebhardt W, Thevis M. Anabolic, doping, and lifestyle drugs, and selected metabolites in wastewater-detection, quantification, and behaviour monitored by high-resolution MS and MS(n) before and after sewage treatment. Anal Bioanal Chem. 2010;398(3):1207-29.

44. Reid MJ, Langford KH, Grung M, et al. Estimation of cocaine consumption in the community: a critical comparison of the results from three complimentary techniques. BMJ Open. 2012;2(6).

45. Bahrke MS, Yesalis CE. Abuse of anabolic androgenic steroids and related substances in sport and exercise. Curr Opin Pharmacol. 2004;4(6):614-20.

46. Bahrke MS, Yesalis CE, Kopstein AN, et al. Risk factors associated with anabolic-androgenic steroid use among adolescents. Sports Med. 2000;29(6):397-405.
47. Castillo EM, Comstock RD. Prevalence of use of performanceenhancing substances among United States adolescents. Pediatr Clin North Am. 2007;54(4):663-75 (ix-x).

48. Kindlundh AM, Isacson DG, Berglund L, et al. Doping among high school students in Uppsala, Sweden: a presentation of the attitudes, distribution, side effects, and extent of use. Scand J Soc Med. 1998;26(1):71-4.

49. Laure $\mathrm{P}$, Binsinger C. Doping prevalence among preadolescent athletes: a 4-year follow-up. Br J Sports Med. 2007;41(10): 660-3 (discussion 3).

50. Sjoqvist F, Garle M, Rane A. Use of doping agents, particularly anabolic steroids, in sports and society. Lancet. 2008; 371(9627):1872-82.

51. van Amsterdam J, Opperhuizen A, Hartgens F. Adverse health effects of anabolic-androgenic steroids. Regul Toxicol Pharmacol. 2010;57(1):117-23.

52. vandenBerg P, Neumark-Sztainer D, Cafri G, et al. Steroid use among adolescents: longitudinal findings from Project EAT. Pediatrics. 2007;119(3):476-86.

53. Nilsson S, Baigi A, Marklund B, et al. The prevalence of the use of androgenic anabolic steroids by adolescents in a county of Sweden. Eur J Public Health. 2001;11(2):195-7.

54. Terney R, McLain LG. The use of anabolic steroids in high school students. Am J Dis Child. 1990;144(1):99-103.

55. Papadopoulos FC, Skalkidis I, Parkkari J, et al. Doping use among tertiary education students in six developed countries. Eur J Epidemiol. 2006;21(4):307-13.

56. Wanjek B, Rosendahl J, Strauss B, et al. Doping, drugs and drug abuse among adolescents in the State of Thuringia (Germany): prevalence, knowledge and attitudes. Int $\mathrm{J}$ Sports Med. 2007;28(4):346-53.

57. Windsor R, Dumitru D. Prevalence of anabolic steroid use by male and female adolescents. Med Sci Sports Exerc. 1989;21(5): 494-7.

58. Yesalis CE, Bahrke MS. Anabolic-androgenic steroids. Current issues. Sports Med. 1995;19(5):326-40.

59. Thevis M, Sauer M, Geyer H, et al. Determination of the prevalence of anabolic steroids, stimulants, and selected drugs subject to doping controls among elite sport students using analytical chemistry. J Sports Sci. 2008;26(10):1059-65.

60. Melnik BC. Androgen abuse in the community. Curr Opin Endocrinol Diabetes Obes. 2009;16(3):218-23.

61. Baker JS, Graham M, Davies B. Gym users and abuse of prescription drugs. J R Soc Med. 2006;99(7):331-2.

62. Baker JS, Graham MR, Davies B. Steroid and prescription medicine abuse in the health and fitness community: a regional study. Eur J Intern Med. 2006;17(7):479-84.

63. Evans NA. Current concepts in anabolic-androgenic steroids. Am J Sports Med. 2004;32(2):534-42.

64. Bolding G, Sherr L, Elford J. Use of anabolic steroids and associated health risks among gay men attending London gyms. Addiction. 2002;97(2):195-203.

65. Da Silva PR, Machado LC Jr, Figueiredo VC, et al. Prevalence of the use of anabolic agents among strength training apprentices in Porto Alegre, RS. Arq Bras Endocrinol Metabol. 2007;51(1):104-10.

66. Graham MR, Davies B, Grace FM, et al. Anabolic steroid use: patterns of use and detection of doping. Sports Med. 2008;38(6):505-25.

67. Striegel H, Simon P, Frisch S, et al. Anabolic ergogenic substance users in fitness-sports: a distinct group supported by the health care system. Drug Alcohol Depend. 2006;81(1): $11-9$.

68. Tricker R, O'Neill MR, Cook D. The incidence of anabolic steroid use among competitive bodybuilders. J Drug Educ. 1989;19(4):313-25. 
69. Kanayama G, Gruber AJ, Pope HG Jr, et al. Over-the-counter drug use in gymnasiums: an underrecognized substance abuse problem? Psychother Psychosom. 2001;70(3):137-40.

70. Petroczi A, Aidman EV, Hussain I, et al. Virtue or pretense? Looking behind self-declared innocence in doping. PLoS One. 2010;5(5):e10457.

71. Petroczi A, Uvacsek M, Nepusz T, et al. Incongruence in doping related attitudes, beliefs and opinions in the context of discordant behavioural data: in which measure do we trust? PLoS One. 2011;6(4):e18804.

72. Striegel H, Ulrich R, Simon P. Randomized response estimates for doping and illicit drug use in elite athletes. Drug Alcohol Depend. 2010;106(2-3):230-2.

73. Secades-Villa R, Fernandez-Hermida JR. The validity of selfreports in a follow-up study with drug addicts. Addict Behav. 2003;28(6): 1175-82.

74. Stone AL, Latimer WW. Adolescent substance use assessment: concordance between tools using self-administered and interview formats. Subst Use Misuse. 2005;40(12):1865-74.

75. Goldman B, Bush P, Klatz R. Death in the locker room. United States: Icarus Press; 1984.

76. Connor J, Woolf J, Mazanov J. Would they dope? Revisiting the Goldman dilemma. Br J Sports Med. 2013;47(11):697-700.

77. Lensvelt-Mulders G, Hox J, Van der Heijden P, et al. Metaanalysis of randomized response research: thirty-five years of validation. Sociol Methods Res. 2005;33:319-48.

78. Lensvelt-Mulders G, Hox J, Van der Heijden P. How to improve the efficiency of randomized response designs. Qual Quant. 2005;39:253-65.

79. Pitsch W, Emrich E, Klein M. Doping in elite sports in Germany: results of a www survey. Eur J Sport Soc. 2007;4(2): 89-102.

80. Stubbe JH, Chorus AMJ, Frank LE, et al. Prevalence of use of performance enhancing drugs by fitness center members. Drug Test Anal. 2013;6(5):434-8.

81. Simon P, Striegel H, Aust F, et al. Doping in fitness sports: estimated number of unreported cases and individual probability of doping. Addiction. 2006;101(11):1640-4.

82. Seiler S, Beneke R, Halson SL, et al. Is doping-free sport a Utopia? Int J Sports Physiol Perform. 2013;8(1):1-3.

83. Zhong W, Wu H, Li L. Olympics: some facts about Ye Shiwen's swim. Nature. 2012;488(7412):459.

84. Vayer A. La preuve par 21. 2013 [17 June 2013]; Available from: http://www.alternativeditions.com/la-preuve-par-21/.

85. Savage M. Armstrong in context. 2012 [17 June 2013]; Available from: http://www.phys.washington.edu/users/savage/Cycling/ LookingAtTheData/AIC.html.

86. Tucker R, Dugas J. The anatomy of a climb: Contador on the Verbier-its place in Tour climbing "history"; 2009 [17 June 2013]; Available from: http://www.sportsscientists.com/2009/ 07/tour-2009-contador-climb.html.

87. Noakes TD. Tainted glory-doping and athletic performance. N Engl J Med. 2004;351(9):847-9.

88. Seiler S, De Koning JJ, Foster C. The fall and rise of the gender difference in elite anaerobic performance 1952-2006. Med Sci Sports Exerc. 2007;39(3):534-40.

89. Hartgens F, Kuipers H. Effects of androgenic-anabolic steroids in athletes. Sports Med. 2004;34(8):513-54.

90. Berthelot G, Tafflet M, El Helou N, et al. Athlete atypicity on the edge of human achievement: performances stagnate after the last peak, in 1988. PLoS One. 2010;5(1):e8800.
91. Berthelot G, Thibault V, Tafflet M, et al. The citius end: world records progression announces the completion of a brief ultraphysiological quest. PLoS One. 2008;3(2):e1552.

92. Lippi G, Banfi G, Favaloro EJ, et al. Updates on improvement of human athletic performance: focus on world records in athletics. Br Med Bull. 2008;87:7-15.

93. Lodewijkx HF, Brouwer B. Some empirical notes on the epo epidemic in professional cycling. Res Q Exerc Sport. 2011; 82(4):740-54.

94. El Helou N, Berthelot G, Thibault V, et al. Tour de France, Giro, Vuelta, and classic European races show a unique progression of road cycling speed in the last 20 years. J Sports Sci. 2010; 28(7):789-96.

95. Ernst S, Simon P. A quantitative approach for assessing significant improvements in elite sprint performance: has IGF-1 entered the arena? Drug Test Anal. 2013;5(6):384-9.

96. De Rijckaert E. zaak Festina-Het recht van antwoord van dokter Eric Rijckaert [The Festina case-the right to an answer by doctor Eric Rijckaert]. Belgium: Uitgeverij Lannoo NV; 2000.

97. Dekker T. Schoon genoeg [Clean enough]. Amsterdam: Arbeiderspers; 2011.

98. Hamilton T, Coyle D. The secret race-inside the hidden world of the Tour de France: doping, cover-ups, and winning at all costs. USA: Bantam Books; 2012.

99. Millar D, Whittle J. Racing through the dark. London: Orion Books; 2011.

100. Matschiner S, Behr M. Grenzwertig: Aus dem Leben eines Dopingdealers [Threshold-worthy: out of the life of a doping dealer]. Germany: Riva Sportverlag; 2011.

101. Canseco J. Juiced: wild times, rampant' roids, smash hits, and how baseball got big. USA: William Morrow; 2005.

102. Lentillon-Kaestner V, Carstairs C. Doping use among young elite cyclists: a qualitative psychosociological approach. Scand J Med Sci Sports. 2010;20(2):336-45.

103. Ohl F, Fincoeur B, Lentillon-Kaestner V, et al. The socialization of young cyclists and the culture of doping. Int Rev Sociol Sport. Epub 24 July 2013.

104. Petroczi A, Mazanov J, Nepusz T, et al. Comfort in big numbers: does over-estimation of doping prevalence in others indicate self-involvement? J Occup Med Toxicol. 2008;3:19.

105. Press A. WADA: 1 in 10 may be doping. 2012 [updated 30 May 2013]; Available from: http://espn.go.com/olympics/story/_/id/ 7550694/wada-says-research-indicates-1-10-athletes-doping.

106. Donovan RJ, Egger G, Kapernick V, et al. A conceptual framework for achieving performance enhancing drug compliance in sport. Sports Med. 2002;32(4):269-84.

107. Morente-Sanchez J, Zabala M. Doping in sport: a review of elite athletes' attitudes, beliefs, and knowledge. Sports Med. 2013;43(6):395-411.

108. Marclay F, Grata E, Perrenoud L, et al. A one-year monitoring of nicotine use in sport: frontier between potential performance enhancement and addiction issues. Forensic Sci Int. 2011; 213(1-3):73-84.

109. Puffer JC. The use of drugs in swimming. Clin Sports Med. 1986;5(1):77-89.

110. SportAccord. Definition of sport. Lausanne, Switzerland 2013 [30 May 2013]; Available from: http://www.sportaccord.com/ en/members/definition-of-sport/. 